\title{
Severe bronchopulmonary dysplasia improved by noninvasive positive pressure ventilation: a case report
}

Christian Mann ${ }^{1,2^{*}}$ and Walter Bär, ${ }^{1,2}$

\begin{abstract}
Introduction: This is the first report to describe the feasibility and effectiveness of noninvasive positive pressure ventilation in the secondary treatment of bronchopulmonary dysplasia.

Case presentation: A former male preterm of Caucasian ethnicity delivered at 29 weeks gestation developed severe bronchopulmonary dysplasia. At the age of six months he was in permanent tachypnea and dyspnea and in need of $100 \%$ oxygen with a flow of $2.0 \mathrm{~L} /$ minute via a nasal cannula. Intermittent nocturnal noninvasive positive pressure ventilation was then administered for seven hours daily. The ventilator was set at a positive endexpiratory pressure of $6 \mathrm{cmH}_{2} \mathrm{O}$, with pressure support of $4 \mathrm{cmH}_{2} \mathrm{O}$, trigger at $1.4 \mathrm{~mL} / \mathrm{second}$, and a maximum inspiratory time of 0.7 seconds. Over the course of seven weeks, the patient's maximum daytime fraction of inspired oxygen via nasal cannula decreased from 1.0 to 0.75 , his respiratory rate from 64 breaths/minute to 50 breaths/minute and carbon dioxide from $58 \mathrm{mmHg}$ to $44 \mathrm{mmHg}$.

Conclusion: Noninvasive positive pressure ventilation may be a novel therapeutic option for established severe bronchopulmonary dysplasia. In the case presented, noninvasive positive pressure ventilation achieved sustained improvement in ventilation and thus prepared our patient for safe home oxygen therapy.
\end{abstract}

\section{Introduction}

Although there is some evidence that nasal noninvasive ventilation has the potential to reduce the incidence of bronchopulmonary dysplasia (BPD) in preterm newborns [1-5], there have been no studies of nasal noninvasive positive pressure ventilation (NIPPV) in former preterm infants with an established diagnosis of BPD requiring high oxygen concentrations.

The main pathophysiological finding in BPD is a low functional residual capacity accompanied by inefficient gas mixing. Respiratory rate is increased [6]. Small airway function may worsen during the first year [7]. Significant gas trapping is found in some BPD infants $[8,9]$. We report the response to intermittent nocturnal therapy with nasal NIPPV in an infant with severe BPD.

\footnotetext{
* Correspondence: christian.mann@ksgr.ch

'Neonatal and Pediatric Intensive Care Unit, Graubuenden Cantonal Hospital, Loestr 170, CH-7000 Chur, Switzerland

Full list of author information is available at the end of the article
}

\section{Case presentation}

Our patient was a male preterm of Caucasian ethnicity, born at 29 weeks and one day gestation by Caesarean section from a spontaneous dichorionic diamniotic twin pregnancy complicated by preterm premature rupture of the membranes with near-total loss of fluid nine days before delivery. His birth weight was $940 \mathrm{~g}$. A chest X-ray showed pulmonary hypoplasia and grade 3 hyaline membrane disease. Surfactant (beractant $100 \mathrm{mg} / \mathrm{kg}$ ) was given one hour after birth and repeated 24 hours later.

The patient was started on high frequency oscillatory ventilation, with highest mean airway pressure 22 $\mathrm{cmH}_{2} \mathrm{O}$ on day one, and then switched to pressure-controlled synchronized intermittent mandatory ventilation on day 20 (highest peak inspiratory pressure 24 $\mathrm{cmH}_{2} \mathrm{O}$ ). Inhaled nitric oxide was delivered for five days in decreasing amounts (starting on day one with 26 ppm).

A left pneumothorax was drained on day four. The clinical course was complicated by ventilator-associated pneumonia on day 15. Tracheal aspirates grew

\section{Biomed Central}


coagulase-negative Staphylococci and Enterobacter cloacae. Treatment consisted of piperacillin and tazobactam with fusidic acid for two weeks. Extubation was successful on day 26 after a two-day course of dexamethasone. Ventilatory support was continued with nasal continuous positive airway pressure (nCPAP; $8 \mathrm{cmH}_{2} \mathrm{O}$ ). BPD was diagnosed at postmenstrual age 36 weeks. Shortly thereafter, nasal swab cultures from copious upper airway secretions proved colonization with Stenotrophomonas maltophilia, Escherichia coli as well as Staphylococcus aureus which was treated with a twoweek course of oral sulfamethoxazole plus trimethoprim and rifampin.

After 10 weeks nCPAP was switched to nasal cannula flow of $2 \mathrm{~L} /$ minute with a fraction of inspired oxygen $\left(\mathrm{FiO}_{2}\right)$ of 0.5. Pulse oximetry target was set at arterial oxygen saturation $\left(\mathrm{SaO}_{2}\right) \geq 90 \%$. During subsequent weeks the oxygen concentration had to be increased to a $\mathrm{FiO}_{2}$ of 1.0 due to progressive deterioration of gas exchange. At the age of six months our patient was in constant dyspnea and tachypnea. Spontaneous inspiratory time was markedly shortened. Streaky densities and cystic areas on a chest X-ray confirmed the diagnosis of severe BPD. Echocardiography revealed concomitant pulmonary hypertension with a tricuspid regurgitation pressure gradient up to $30 \mathrm{mmHg}$. The $\mathrm{FiO}_{2} 1.0$ requirement created a high risk of urgent reintubation in the event of sudden desaturation. The boy's increasing drive to move around ruled out reintroducing nCPAP.

A ventilator set to NIPPV was installed providing nocturnal ventilatory support for an average of seven hours every night. Ventilator settings are presented in Table 1. For the first 18 days, sedation was provided with chloral hydrate in decreasing amounts from $52 \mathrm{mg} / \mathrm{kg}$ to $7 \mathrm{mg} /$ $\mathrm{kg}$ per evening dose.

The features of the NIPPV device included a limited dead space, highly sensitive automated circuit leak compensation, and high trigger sensitivity. NIPPV was administered via a nasal mask in a semirecumbent position to enhance air entry into West zones 1 and 2 and to diminish expansion of the radiologically over-distended lung bases.

In the course of seven weeks of intermittent nocturnal NIPPV, the spontaneous respiratory rate decreased from

\section{Table 1 Ventilator settings for NIPPV}

\begin{tabular}{ll}
\hline Pressure support & $4 \mathrm{cmH}_{2} \mathrm{O}$ \\
Positive end-expiratory pressure & $6 \mathrm{cmH}_{2} \mathrm{O}$ \\
Trigger & $1.4 \mathrm{~mL} / \mathrm{second}$ \\
Ramp & $25 \mathrm{~ms}$ \\
Expiratory trigger sensitivity & $10 \%$ \\
Backup respiratory rate & $8 /$ minute \\
Maximum inspiratory time & 0.7 seconds \\
\hline
\end{tabular}

64 breaths/minute to 50 breaths/minute, morning (postNIPPV) carbon dioxide dropped from $58 \mathrm{mmHg}$ to 44 $\mathrm{mmHg}$, and-most importantly-nasal cannula maximum $\mathrm{FiO}_{2}$ decreased from 1.0 to 0.75 and the minimum $\mathrm{FiO}_{2}$ from 0.8 to 0.6 (Figure 1). At this point, NIPPV was stopped and the baby was discharged on home oxygen (flow rate $0.25 \mathrm{~L} /$ minute) at the postnatal age of eight months. His weight increased by $200 \mathrm{~g}$ per week during NIPPV therapy and reached $7490 \mathrm{~g}$ at discharge.

Two intercurrent lower respiratory tract infections were managed on an outpatient basis. Our patient was completely weaned off oxygen nine months after discharge at the age of 17 months.

Neurological examination at the age of one year showed less delay in the mental scale than in the psychomotor scale (Bayley II) with scores of 76 and 56, respectively. Free walking was achieved at 22 months of age.

\section{Conclusion}

The clinical course of this ex-preterm boy suggests that secondary NIPPV therapy has the potential to improve severe BPD. A course of nocturnal intermittent NIPPV in a timely manner (seven weeks) improved ventilation and reduced oxygen need to a degree which provided sufficient safety for subsequent home oxygen therapy. Its positive effect was essential for our patient's discharge after eight months of hospital stay. In terms of practicability, NIPPV was superior to nCPAP in that it reliably avoided hypoventilation when the child initially needed sedation to tolerate a nasal mask.

According to the literature, a bundle of different mechanisms may have contributed to the improvement observed. Synchronized NIPPV is known to increase functional residual capacity [4], enhance ventilation uniformity [5], improve respiratory drive [10,11], lead to greater lung recruitment [12] and decrease inspiratory effort and respiratory work in comparison to continuous flow nCPAP $[13,14]$. The duration of ventilatory support is shorter with primary use of NIPPV than with nCPAP [15].

We think this observation provides useful information on NIPPV in established BPD before larger randomized studies are performed on this topic. Further studies incorporating lung function tests should identify the level of respiratory support at which the repetitive stimulus of nocturnal NIPPV exerts most of its positive influence. It would be interesting to find out how NIPPV propagates lung remodelling or if it even has the potential to accelerate lung maturation in severe BPD.

\section{Consent}

Written informed consent was obtained from the patient's parents for publication of this case report. A 

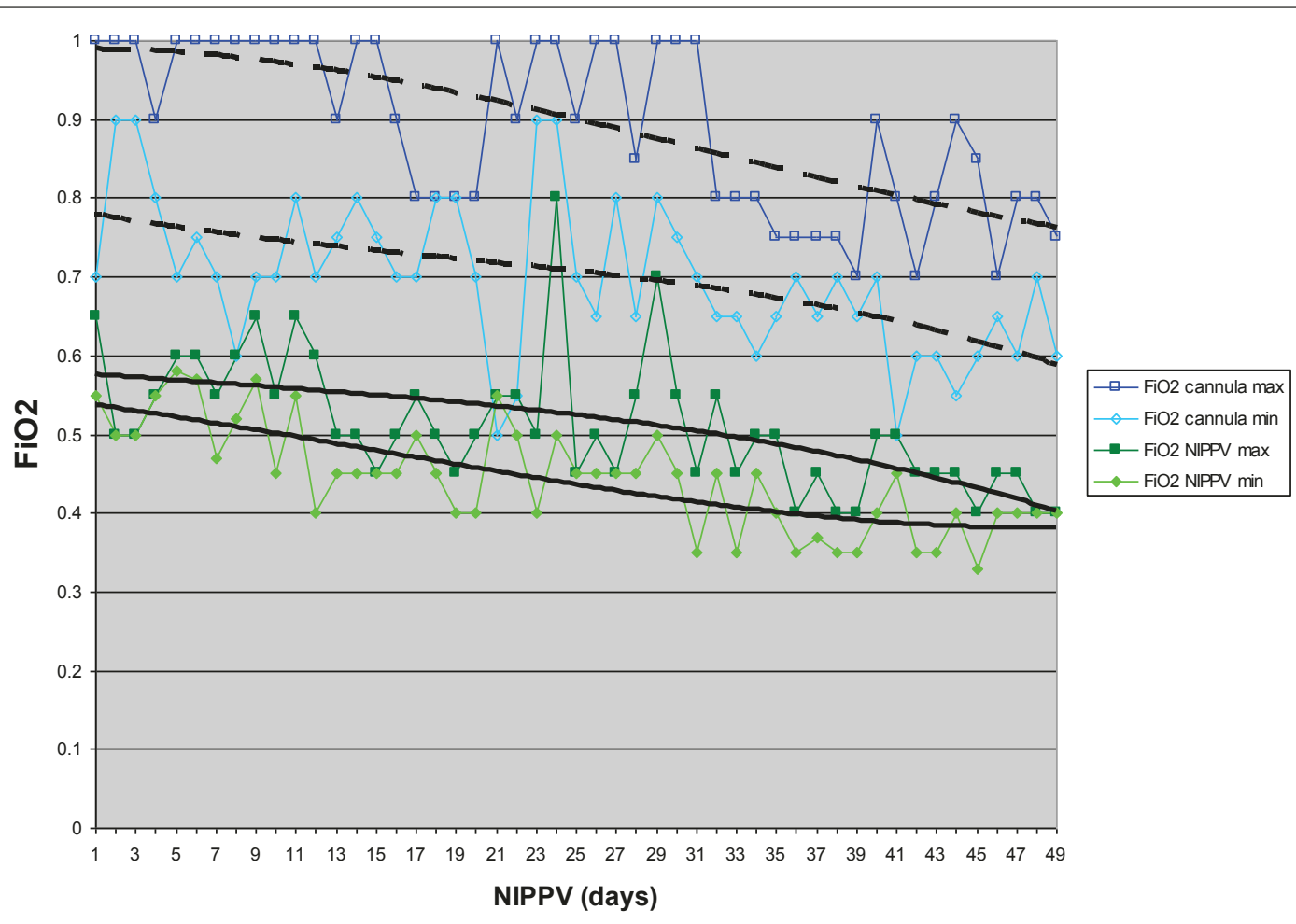

Figure 1 Decrease in $\mathrm{FiO}_{2}$ requirement over seven weeks of nocturnal NIPPV. Open rectangles and blue lines: oxygen concentrations (maximum and minimum for each day) delivered via nasal cannula during daytime; full rectangles and green lines: oxygen concentrations for nocturnal NIPPV. Oxygen saturation target was set at $\geq 90 \%$.

copy of the written consent is available for review by the Editor-in-Chief of this journal.

\section{Acknowledgements}

The authors thank Axel Zolkos for his technical skills in administering noninvasive ventilation to this infant and for his support in extracting patient data from the chart.

\section{Author details}

${ }^{1}$ Neonatal and Pediatric Intensive Care Unit, Graubuenden Cantonal Hospital, Loestr 170, CH-7000 Chur, Switzerland. ${ }^{2}$ College for Intensive Care, Emergency and Anesthesia Nursing, Children's Hospital, University Clinic, Steinwiesstrasse 75, CH-8032 Zuerich, Switzerland.

\section{Authors' contributions}

WB led the decision to institute NIPPV in this case. WB and CM analyzed and interpreted the patient data. CM reviewed the literature and wrote the manuscript. Both authors read and approved the final manuscript.

\section{Competing interests}

The authors declare that they have no competing interests.

Received: 18 April 2011 Accepted: 6 September 2011

Published: 6 September 2011

\section{References}

1. De Paoli AG, Davis PG, Lemyre B: Nasal continuous positive airway pressure versus nasal intermittent positive pressure ventilation for preterm neonates: a systematic review and meta-analysis. Acta Paediatr 2003, 92:70-75.
2. Kulkarni A, Ehrenkranz RA, Bhandari V: Effect of introduction of synchronized nasal intermittent positive-pressure ventilation in a neonatal intensive care unit on bronchopulmonary dysplasia and growth in preterm infants. Am J Perinatol 2006, 23:233-240.

3. Kugelman A, Feferkorn I, Riskin A, Chistyakov I, Kaufman B, Bader D: Nasal intermittent mandatory ventilation versus nasal continuous positive airway pressure for respiratory distress syndrome: a randomized, controlled, prospective study. J Pediatr 2007, 150:521-526.

4. Owen LS, Morley CJ, Davis PG: Neonatal nasal intermittent positive pressure ventilation: what do we know in 2007? Arch Dis Child Fetal Neonatal Ed 2007, 92:F414-F418.

5. Deakins KM: Bronchopulmonary dysplasia. Respir Care 2009, 54:1252-1262.

6. Hjalmarson $\mathrm{O}$, Sandberg KL: Lung function at term reflects severity of bronchopulmonary dysplasia. J Pediatr 2005, 146:86-90.

7. Hofhuis W, Huysman MW, van der Wiel EC, Holland WP, Hop WC, Brinkhorst G, de Jongste JC, Merkus PJ: Worsening of V'maxFRC in infants with chronic lung disease in the first year of life: a more favorable outcome after high-frequency oscillation ventilation. Am J Respir Crit Care Med 2002, 166:1539-1543.

8. Wauer RR, Maurer T, Nowotny T, Schmalisch G: Assessment of functional residual capacity using nitrogen washout and plethysmographic techniques in infants with and without bronchopulmonary dysplasia. Intensive Care Med 1998, 24:469-475.

9. Hülskamp G, Pillow JJ, Dinger J, Stocks J: Lung function tests in neonates and infants with chronic lung disease of infancy: functional residual capacity. Pediatr Pulmonol 2006, 41:1-22.

10. Moretti C, Gizzi C, Papoff P, Lampariello S, Capoferri M, Calcagnini G, Bucci G: Comparing the effects of nasal synchronized intermittent positive pressure ventilation (nSIPPV) and nasal continuous positive airway pressure (nCPAP) after extubation in very low birth weight infants. Early Hum Dev 1999, 56:167-177. 
11. Lin CH, Wang ST, Lin YJ, Yeh TF: Efficacy of nasal intermittent positive pressure ventilation in treating apnea of prematurity. Pediatr Pulmonol 1998, 26:349-353.

12. Courtney SE, Pyon KH, Saslow JG, Arnold GK, Pandit PB, Habib RH: Lung recruitment and breathing pattern during variable versus continuous flow nasal continuous positive airway pressure in premature infants: an evaluation of three devices. Pediatrics 2001, 107(2):304-308.

13. Ali N, Claure N, Alegria X, D'Ugard C, Organero R, Bancalari E: Effects of non-invasive pressure support ventilation (NI-PSV) on ventilation and respiratory effort in very low birth weight infants. Pediatr Pulmonol 2007, 42:704-710.

14. Courtney SE, Aghai ZH, Saslow JG, Pyon KH, Habib RH: Changes in lung volume and work of breathing: A comparison of two variable-flow nasal continuous positive airway pressure devices in very low birth weight infants. Pediatr Pulmonol 2003, 36(3):248-252.

15. Lista G, Castoldi F, Fontana P, Daniele I, Cavigioli F, Rossi S, Mancuso D, Reali R: Nasal continuous positive airway pressure (CPAP) versus bi-level nasal CPAP in preterm babies with respiratory distress syndrome: a randomised control trial. Arch Dis Child Fetal Neonatal Ed 2010, 95(2): F85-89.

doi:10.1186/1752-1947-5-435

Cite this article as: Mann and Bär: Severe bronchopulmonary dysplasia improved by noninvasive positive pressure ventilation: a case report. Journal of Medical Case Reports 2011 5:435.

\section{Submit your next manuscript to BioMed Central and take full advantage of:}

- Convenient online submission

- Thorough peer review

- No space constraints or color figure charges

- Immediate publication on acceptance

- Inclusion in PubMed, CAS, Scopus and Google Scholar

- Research which is freely available for redistribution

Submit your manuscript at www.biomedcentral.com/submit 